Document downloaded from:

http://hdl.handle.net/10251/52736

This paper must be cited as:

Redon Climent, A.; Navarro-Peris, E.; M. Pitarch; José Gonzálvez-Maciá; José M. Corberán (2014). Analysis and optimization of subcritical two-stage vapor injection heat pump systems. Applied Energy. 124:231-240.

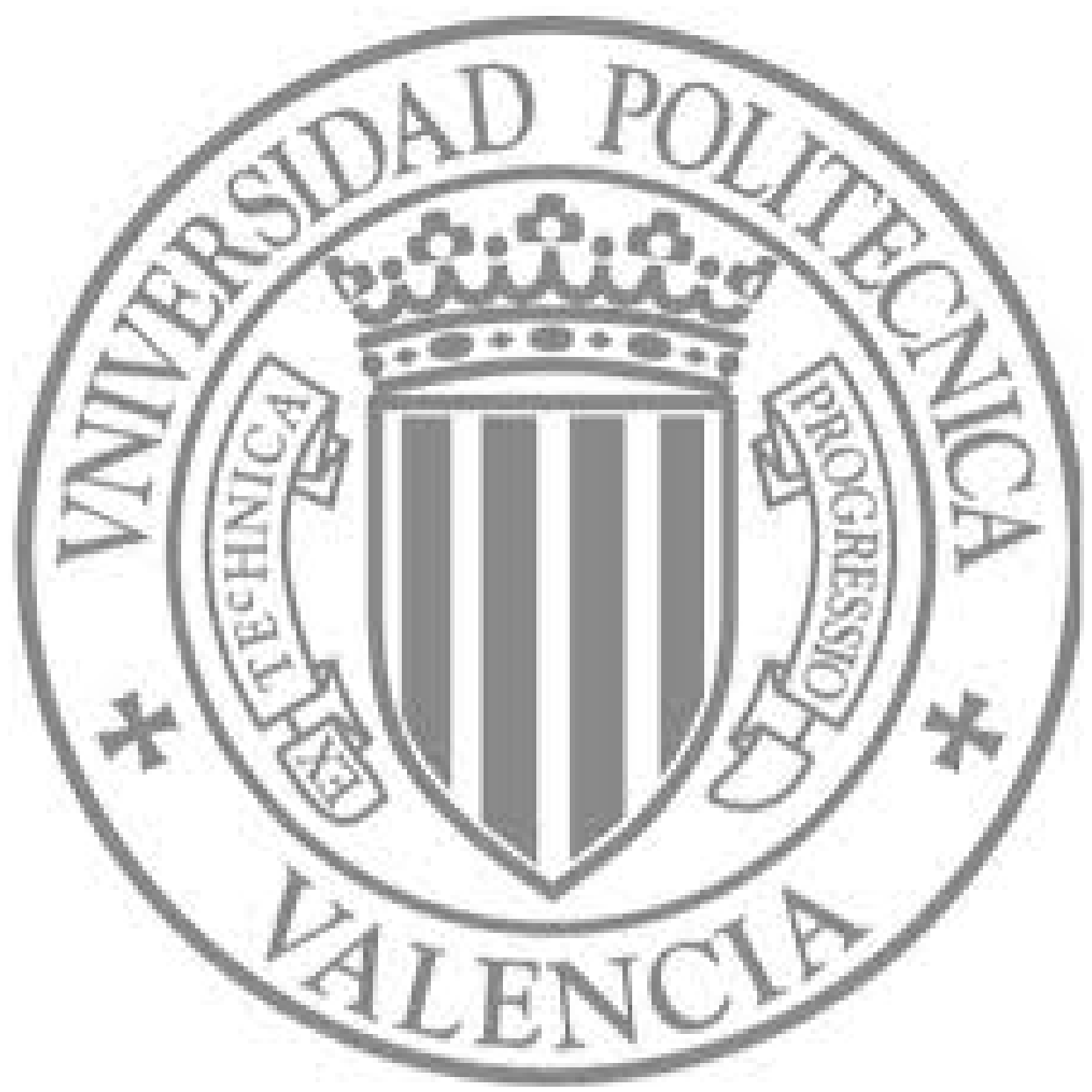

The final publication is available at

http://dx.doi.org/doi:10.1016/j.apenergy.2014.02.066

Copyright Elsevier 


\section{Analysis and optimization of subcritical two-stage vapor injection heat pump systems}

A Redón ${ }^{1}$, E Navarro-Peris ${ }^{1}$, M Pitarch $^{1}$, J Gonzálvez-Macia ${ }^{1}$, JM Corberán $^{1}$

1 - Instituto de Ingeniería Energética. Universitat Politècnica de València. Camino de vera $\mathrm{s} / \mathrm{h}$, 46022. Valencia. España

Tel: +34963879123

e-mail: enava@ter.upv.es

\section{Abstract}

Two of the major problems of heat pump systems working in extreme conditions are the loss of efficiency of the system and the high compressor discharge temperatures which can even impede the correct performance of the machine. One possibility in order to overcome these issues is to perform the compression in two stages. In this frame the use of vapor injection two stage cycles represent an economic and effective solution. The results of using this kind of cycles are the reduction of the pressure ratio of each compression stage, the reduction of the discharge temperature due to the cooling effect provided by the intermediate cooling and the increase of theoretical cycle efficiency. This study analyzes two vapor injection cycles, in terms of the injection conditions for three different refrigerants (R407C, R290 and R22). The work considers the efficiencies of each component and their sensibility to the working conditions. From all the analysis, guidelines for the optimum design and control of such systems are obtained in terms of capacity, COP and discharge temperature criteria.

Keywords: Heat pump, vapor injection, efficiency, simulation, Two-stage. 


\section{Nomenclature}

$\mathrm{C}_{0}$ : Coeficient of geometric mean of pressures. $(\quad \longrightarrow)$

$\mathrm{COP}_{\mathrm{h}}$ : Heating COP

DCOP: Relative difference between heating COP of two stages and one stage cycles.

Disp.ratio: Displacement ratio

$\mathrm{DQ}_{\mathrm{h}}$ : Relative difference between heating capacity of two stages and one stage cycles.

DTb: Bubble temperature difference DTb=Tdiv-Tsec

DTd: Dew temperature difference DTd=Tmain-Tbint

$E_{1}$ : Compressor energy consumption at the first stage

$E_{2}$ :Compressor energy consumption at the second stage

EV-1:Injection expansion valve

EV-2:Evaporator expansion valve

$h_{\text {div }}$ : Enthalpy of the refrigerant at the condenser outlet

$h_{\text {main }}$ : Enthalpy after the division of the main line

$h_{\text {sec }}$ : :Enthalpy after the division of the secondary line

$\dot{m}_{i n j}:$ Injected mass flow rate.

$\dot{m}_{\text {main }}:$ mass flow rate through the evaporator

$\mathrm{P}_{\text {int }}$ : Intermediate pressure

PR:Pressure ratio

$Q_{c}$ : Heating Capacity

Ref: Refrigerant

$r$ : fraction of injected mass flow compared to the total mass flow through the system

$\mathrm{SCOP}_{\text {on }}$ : Seasonal COP in active mode

$S h_{\text {int }}$ : Superheat at the inlet of the second stage

$\mathrm{T}_{\text {disch }}$ : Discharge temperature 
$T_{\text {div }}$ : Temperature of the refrigerant at the condenser outlet

$\mathrm{T}_{\text {sec }}$ : Temperature after the division of the secondary line

$\mathrm{T}_{\text {main }}$ : Temperature after the division of the main line

$\mathrm{T}_{\mathrm{bi}}$ : Bubble temperature at the injection pressure

$T_{d i}$ : Dew temperature at the injection pressure

$\dot{V}$ :Compressor displacement

$\mathrm{x}_{\mathrm{inj}}$ : Injection ratio

$\eta_{c}:$ Compressor efficiency

$\eta_{v}:$ Volumetric efficiency

$\rho_{1}$ : Refrigerant density at the compressor inlet

\section{Introduction}

Air conditioning systems represent an important fraction of the global energy consumption (up to $50 \%$ in residential sector [1]). For that reason, one of the targets of UE for 2020 is the improvement of efficiency in heating and cooling systems. In this framework, the development and optimization of heat pumps with higher efficiency and wider application range is expected to receive an important support [2]. Currently, air-air and air-water systems are widely used but they still have some limitations, especially when the temperature difference between the heat source and the heat sink is large due to the following reasons:

- In heating systems, the heat production is insufficient when the external temperature is low, which is precisely when more heating capacity is required. This reduction in the heating capacity of the heat pump is mainly associated to the decrease on the mass flow of the refrigerant supplied by the compressor when they are working at high pressure ratios. 
- High discharge temperature as a consequence of large pressure ratio: In order to avoid damages to the system, the heat pumps are designed for stopping its activity when the discharge temperature reaches certain level. On that situation, some support systems such as electric heaters or boilers are activated, resulting in a reduction of efficiency.

- $\mathrm{COP}$ of the system is strongly related to the evaporation and condensing temperatures (Carnot efficiency), it rapidly decreases for high pressure ratios (low evaporation temperatures or high condensing temperatures).

- The systems designed for working in this kind of conditions are generally oversized, which leads to a substantial drop in their efficiency when they work in mild conditions.

In the same line, it could be said that nowadays application of heat pumps for producing sanitary hot water with heat pumps and substitute boilers is constrained for HFC by the poor efficiency obtained when the condensing temperature is too high.

For all these applications, some solutions are currently on the market in which efficiency of the system has been improved: Low enthalpy geothermal systems with borehole heat exchangers which reduces the temperature difference between the heat source and the heat sink; cascade systems used in large refrigeration equipment, which increases efficiency of the system by coupling two different refrigeration circuits. Variable speed compressors allows a better coupling of this kind of systems to external conditions and the like. Table 1 summarizes the main alternatives found in literature to increase the application range of refrigeration equipment [3]. 
As is shown in table 1 , the two stages with vapor injection systems have a high potential for improving the performance in extreme working conditions. These systems have been identified as one possible solution for air conditioning market since 1979 [4] [5]. However, its implementation did not get too many impulses until last years. Within this kind of systems, different designs of the circuits have been proposed; however, there are two configurations that can be considered the basis for other more elaborated designs (figure 1). Such systems are so far the most discussed in literature, both theoretically and experimentally and, as far as the knowledge of the authors, they are the only ones for which some component brands propose general directives of design [6].

From the theoretical point of view, the main difference of the vapor injection systems compared to one stage cycles is that their efficiency is not only linked with the temperature of the source and sink but it also depends on how the injection is done. A common assumption is to consider that the lowest consumption of the compressor is reached when the intermediate pressure is equal to the geometric mean of the condensing and evaporation pressure. However, this assumption is only true for an ideal gas, constant compressor efficiency and it only regards to the electric consumption of the compressor, but not to the COP of the system.

Since the 50's, multiple works have arisen trying to describe the optimum intermediate conditions according to criteria closer to real systems. For this purpose non-ideal gas equations and real efficiency curves of the compressors have been introduced. This line of work started with [7], where an expression for the optimum intermediate temperature based on three refrigerants and considering an intermediate superheat equal to zero is given. Within this framework successive works came up [8]-[13], where different conclusions were reached depending on the approach and refrigerant considered. More recently, and driven by the growing interest in the optimization of energetic systems, models of increasing complexity have been developed to estimate the 
optimum intermediate conditions from a global point of view considering the system as a whole. In this trend, it should be cited [14], which evaluated the idea of flash tank cycle, concluding that COP improves considerably for fluids with high heating capacity. [15] models thermodynamically a flash tank system with rotary compressor, finding that R507A and R404A present greater improvement than R134a and R410A. [16] and [17] establish a thermodynamic model of a vapor injection system working with R22 and conclude that the ratio of the injection pressure and the geometric mean of the condensing and evaporating pressure should be 1.2 in order to maximize the cooling capacity of the system. [18] simulates an injection vapor system working with R410A coming to the conclusion that COP can improve between $6 \%$ and $8 \%$ and the compressor can be reduced up to $16 \%$ for the same charge. [19] gives a new design of the injection ports that theoretically can improve capacity and efficiency in $23 \%$ and $12 \%$ respectively, compared with conventional systems. [20]-[22] study injection effects in R22 systems.

Nevertheless, up to the knowledge of the authors, no compressive study which analyzes the optimum intermediate conditions for different refrigerants used in heat pumps (HFCs, HCFCs, $\mathrm{HCs}$ ), define the influence of the different system variables, analyzes theoretically different injection cycles and the performance of the system for a wide range of working conditions have been found. Regarding the last point it should be mentioned that most of the bibliography found is based on two stage systems working with $\mathrm{CO} 2$.

The present work analyzes the optimum working conditions for injection systems in order to give an insight to predesign its different components. The performance of the configurations showed in figure 1 working with R22, R407C and R290, which are refrigerants used in commercial heat pumps, have been analyzed. A sensitivity study of these conditions depending on the working conditions of the system has been done (evaporation temperature). Furthermore, the sensitivity 
of the system to the change of the design conditions is analyzed and an analysis of control strategies in order to optimize the performance of the system. From all this work, basic design guidelines for this type of equipment is given in order to take the maximum advantage of the potential of this kind of cycles.

\section{Description of vapour injection cycles}

In order to fix some concepst for the following sections, in this section outline the main characteristics of vapor injection cycles. These systems extract some refrigerant from the liquid line at the condenser outlet and inject it in a intermediate state of the compression process. They have the same number of contour conditions than one stage system: evaporation temperature, condensing temperature, superheat, subcooling at the outlet of the condenser - assuming the charge of the system as a parameter- and also, the mass flow through the evaporator, which is determined by the displacement volume of the first compressor. Unless otherwise noted, the value of the last three parameters in this work will be: $5 \mathrm{~K}, 5 \mathrm{~K}$ and $18 \mathrm{~m}^{3} / \mathrm{h}$ respectively.

Considering that all these conditions are defined, the performance of an injection cycle will depend on the 4 internal variables of the system: Pressure, mass flow and superheat of the injected gas, and the temperature of the refrigerant at the inlet of EV-2 (see fig 1). Internally, the construction and control of the system has to be designed so that the value of these variables make possible an optimum performance, either in terms of COP, capacity, discharge temperature, or other criteria depending on the application.

With this configuration of the system, the first bound is given by the first law of thermodynamics in the division of the flow in two branches:

$h_{d i v}=(1-r) h_{\text {main }}+r h_{\mathrm{sec}}$ 
Where $h$ is the enthalpy, $r$ the fraction of injected mass flow compared with the total mass of the system. The subscript div is referred to the point where it is produced the division between the mass flow of the main line and the mass flow of the secondary line, main is referred to the flow after the division and before any other interaction with other part of the system and sec is referred to the separated mass flow from the main flow before suffering any interaction with other part of the system (see figure 1).

Therefore, the number of internal independent variables of the injection system are 3 . Considering that the volume of the second stage compressor can be sized by design on the basis of the cycle optimum value, the injected mass flow is selected as the dependent variable from among the initial 4.

Assuming that the change in the flow through both lines is produced by thermic interaction between them, it is possible to add two additional restrictions, which would limit the conditions that the system can reach.

$T_{d i v} \geq T_{\mathrm{sec}}$

$T_{b i} \leq T_{\text {main }}$

Where $T$ is the temperature and the subscript $b i$ is referred to the bubble point at the intermediate pressure. These boundaries would affect the superheat before the entrance to the second compression and the subcooling with which the refrigerant of the main circuit enters to the EV-2 valve. Thus, there are a bound and two restictions among the 4 initial variables.

The analysis of the effects of the injection conditions on the system has been done in terms of heating COP and heating capacity: 


$$
\dot{Q}=\dot{m}_{c} \cdot\left(h_{4}-h_{5}\right)
$$

$$
C O P=\frac{\left(h_{4}-h_{5}\right)}{E_{1}+E_{2}}=\frac{\left(h_{4}-h_{5}\right)}{(1-r)\left(h_{2}-h_{1}\right)+\left(h_{4}-h_{3}\right)}
$$

Where $E_{i}$ is the power consumption in the corresponding stage, $\dot{m}_{c}$ is the mass flow in the condenser and the subindex of the $\mathrm{h}$ represent the entalpies at the corresponding points of figure 1. The variables have been defined for a heating application, since it is the most common working field of this type of cycles.

Up to here, the proposed relations are independent of how the injection is physically implemented. Later on, this study is focused on the following configurations of figure 1 (economizer system and flash tank). There is an additional bound for a system with a defined heat exchanger(figure 1a), and in that case the number of independent variables is reduced to 2 . The calculation of the heat exchanger has been done according to [24]. Commonly these independent variables are the injection superheat and the intermediate pressure. The additional subcooling reached in the economizer is determined by them and by the equations governing the heat transfer of the economizer.

For the flash tank system, the inlet and outlet conditions are limited by the following bonds:

$T_{7}=T_{b i}$

$T_{8}=T_{d i}$

Where the subscript $d i$ is referred to the dew temperature in the injection conditions and the temperature subindex 7 and 8 represents the temperature at the corresponding points of the figure $1 \mathrm{~b}$. Equation (6) is equivalent to the limit given for the equation (3). In this system, as the 
restrictions (2) and (3) are fixed, the only independent parameter is the intermediate working pressure. This is not the case when transcritical cycles are considered as in that kind of systems the gas-cooler pressure is also a variable.

Taking into account all these limitations, the optimum intermediate pressure and injection temperature is determined on the next section and based on that optimum compressor volume ratios and control strategies are defined.

Finally, it is convenient to point out that the influence of pressure ratio on compressor performance could have a great influence on the global behaviour of the system. In order to take this effect into account, on the section 3.2 the parametric curves (8) and (9) have been used in order to determine the compressor efficiency and the volumetric efficiency.

$$
\begin{aligned}
& \eta_{c}=\frac{\dot{m}\left(h_{2 i s}-h_{1}\right)}{E_{t}}=a\left(1-e^{-\frac{P R-d}{b}}\right)-c \ln (P R+1) \\
& \eta_{v}=\frac{\dot{m}}{\rho_{1} \dot{V}}=A \cdot P R+B
\end{aligned}
$$

Where $P R$ represents the compression ratio; $a, b, c, d$ and $A, B$ are parameters of compressor efficiency and volumetric efficiency, respectively, that depend on the compressor seleced. These generic curves are obtained from catalogue data for a one stage compressor from Danfoss CC. The parameters for that compressor are shown in Table 2.

At this point, it is convenient to point out that the most relevant aspect of these curves is more related to the analysis of COP degradation than with the definition of the real optimum as compressor design can be done in order to fit the thermodynamic optimum for a given condition. 


\section{Results and discussion.}

\subsection{Optimization of working conditions for ideal compressors.}

Based on the analysis of the previous section, the intermediate injection conditions for the working point $(-8,65)$ have been optimized for the refrigerants: R22, R407C and R290.

The working point is referred to a system for sanitary hot water production. The refrigerants have been selected considering their adequate thermodynamic properties to work with high condensation temperature (critical point over 90) and their suitable volumetric properties.

Figure 2 shows the COP value for refrigerants R290 and R22 as a function of $T_{\text {div }}-T_{\text {sec }}\left(D T_{d}\right)$ and $T_{\text {main }}-T_{b i}\left(D T_{b}\right)$ which are the restrictions of equations (2) and (3) respectively. For both refrigerants, COP increases as $\mathrm{DT}_{\mathrm{b}}$ tends to 0 . Regarding the influence of $D T_{d}$, two different behaviors can be observe: The COP increases as $\mathrm{DT}_{d}$ tends to zero for refrigerant R290 while for R22 this trend is not observed so clearly, this different behavior is a consequence of the thermodynamic properties of each fluid. The influence on COP of $\mathrm{DT}_{\mathrm{b}}$ is higher than the influence of $\mathrm{DT}_{\mathrm{d}}$. Therefore, from the optimization point of view it will be more interesting to focus on the values of $D T_{b}$ than on the values of $D T_{d}$.

For each refrigerant, the equal condition of equations (2) and (3) is reached at different values of intermediate pressure which correspond to different displacement ratios for the compressor. With the purpose of representing the intermediate pressure with a non-dimensional parameter and in order to be able to compare the obtained results for different refrigerants, the coefficient $\mathbf{C}_{\mathrm{o}}$ of equation (10) has been defined. This coefficient relates the intermediate pressure with the geometric mean of the evaporation and condensing pressures. 
$C_{o}=\frac{P_{\mathrm{int}}}{\sqrt{P_{e} \cdot P_{c}}}$

Where $\mathrm{P}_{\text {int }}$ is the intermediate pressure, $\mathrm{P}_{\mathrm{e}}$ is the evaporation pressure and $\mathrm{P}_{\mathrm{c}}$ is the condensing pressure.

Figure 3 represents the COP as a function of displacement ratio for R290. The system has an optimum COP for a specific displacement ratio; a bad selection of the compressor volumes might lead to losses in COP up to $11 \%$; the decrease in COP is more significant if the displacement ratio is lower than the optimum than if it is higher which is an important factor to take into account in the selection of the compressor volume ratio.

Table 3 shows the results for the optimum points with the three refrigerants in this working condition. In order to simplify the calculations, the isothermal lines of the liquid line have been considered as vertical lines.

The value for the optimum intermediate pressure is slightly higher than the geometric mean of condensing and evaporation pressure for all the refrigerants $\left(\mathbf{C}_{\mathbf{o}}>1\right)$, while the displacement ratio in the optimum conditions depends considerably on the refrigerant. Values of $D Q_{h}$ and $D C O P$ (relative difference between the one stage cycle and the two stage cycle) show a great potential for improvement for this kind of cycles.

Once the optimum is established, the next step is to study the systems proposed in figure 1 . The results are shown in Table 4 and Table 5. For the system with economizer (figure 1a) the following design conditions have been supposed: a UA value corresponding to $\Delta \mathrm{T}$ of $5 \mathrm{~K}$ in the heat exchanger (DT_HX in Figure 4) and a fixed superheat at the outlet of heat exchanger of $5 \mathrm{~K}$, assuming that the control of injection is implemented by a thermostatic expansion valve and that the objective of the control strategy is to reduce the compressor discharge temperature. 
These results show that the flash tank system provide greater COP and lower discharge temperature than the system with economizer. The intermediate pressure for the flash tank system is higher and closer to the optimum. This is directly related to the fact that the flash tank is always moving in the line of $\mathrm{DT}_{\mathrm{b}}$ equal to 0 of Figure 2.

In order to analyze the differences between the cycles of figure 1 , in Table 6 , the restriction imposed to the economizer size is released, the displacement of the compressor is fixed to the optimum obtained for the flash tank system and the UA value is progressively increased keeping constant the intermediate superheat (total superheat of the refrigerant at the inlet of the second stage, $\mathrm{sh}_{\text {int }}$ in table 4 and 5) and equal to that of the flash tank $(6.795 \mathrm{~K})$. It can be seen how the system tend to the COP of the flash tank system as the heat exchanger area increases, this is directly related with the fact that $\mathrm{DT}_{\mathrm{b}}$ tends to zero. The effect of the economizer size on the capacity shows that using higher economizer, the compressor size could be reduced for a given heating capacity.

According to these results it is possible to conclude that for the design conditions imposed by the the heat exchanger and the thermostatic expansion valve, the flash tank system would present better COP and lower discharge temperature than a system with economizer. For conditions where the intermediate superheat is not fixed the system with economizer would allow an improvement in COP in comparison with the flash tank system overall in those refrigerants that have an increase of COP when $\mathrm{DT}_{d}$ tends to zero (increase injected superheat). Figure 5 shows how the COP increases for refrigerant R290 until a maximum is reached, this optimum value corresponds to $\mathrm{DT}_{\mathrm{d}}$ equal to zero.

The increase in intermediate superheat leads not only to an increase in the COP but also in the discharge temperature. In this case, where an isentropic compression is assumed for each stage, 
the increase in the discharge temperature was 6 degrees (this will be not the case in real systems in which the increment can be significantly greater, as it is shown later). Refrigerants with low discharge temperature as R290 and R1234yf have wider potential for COP improvement than refrigerant with high discharge temperature like R410A.

\subsection{Real systems.}

On the previous section, optimization of vapor injection cycles has been studied considering nominal conditions but in a real system the heat pump working conditions change along the year. In this section, the influence of the change of the external conditions (evaporating an condensign temperatures) on the performance of an injection system is analyzed. In this study compressor efficiency no longer can be considered constant and expressions (8) and (9) have been considered for the estimantion of the influence of external conditions on compressor performance.

In order to perform the analysis, firstly, the system of figure 1a with an intermediate superheat of $5 \mathrm{~K}$ has been optimized at three working conditions so as to see how the design parameters change ( $\mathbf{C}_{0}$ and displacement ratio). The results in Table 7 show how the optimum displacement ratio varies significantly up to $17 \%$ from those encountered in the ideal case. Regarding $\mathbf{C}_{0}$, it can be seen how the optimum intermediate pressure gets closer to the geometric mean of the condensing and evaporating. Furthermore it shows the discharge temperature for these non-ideal systems, and for instance the high values of discharge temperature of the refrigerant R22 impede to work at the optimum condition, due to the risk for the compressor reliability.

Secondly, COP degradation of a system designed to work at the conditions $(-8 / 65)$ is evaluated when it works in other conditions. Table 8 shows that the COP differences are less than $1 \%$.

In order to take into account the variation of the environmental conditions along the year the European Norm En 14825 defines the seasonal COP (SCOP). The SCOP weight the COP obtained in 
several working conditions in order to consider the change in the operation conditions of the heat pump along the year, see [25] for more information about this methodology. Therefore, for a real system it is important to design and size the compressor based on SCOP instead of using just the COP value for one operating condition. Figure 6 shows the $\mathrm{SCOP}_{\text {on }}$ value obtained for high temperature application and climate zone A (see [25]) as a function of displacement ratio. It can be seen that for the climate zone $\mathrm{A}$ the $\mathrm{SCOP}_{\text {on }}$ has an optimum value for a displacement ratio of approximately 0.6 . The same evaluation performed with a one stage heat pump using a compressor with the same efficiency gives a $\mathrm{SCOP}_{\text {on }}$ of 2.16 which is significantly lower compared with the values obtained on the figure.

\subsection{Refrigerant charge influence.}

The charge of a refrigeration system without liquid bottle determines the subcooling at the outlet of the condenser. So far, the subcooling has been considered as a prefixed parameter equal to $5 \mathrm{~K}$. This approach is appropriate for an initial analysis but the subcooling influence on the system should be also evaluated. A parametric study has been performed in order to determine influence of this parameter in the selection of the optimum volume ratio. Figure 7 , represents COP as a function of subcooling and volume ratio, the figure shows an increase of the optimum volume ratio as subcooling increases.

Table 9 shows how the increase in the subcooling at the outlet of the condenser always improve the performance of the system, the higher subcooling, higher COP and capacity and lower discharge temperature, injected mass flow and injection pressure. However the subcooling in a real system is limited by economic and technical reasons. 


\subsection{Control strategies.}

On the previous sections, the behavior of two stage systems has been analyzed in terms of performance, but it is important to have a methodology to control the system at any operating point in order to make it works in its optimum.

The operation of the system can be controlled by the expansion valves EV-1 and EV-2 (see figure 1). Hence a relationship between the opening of the valves and other measurable parameters of the system is needed in order to maximize performance. In order to do that and as a first approach a correlation between the opening of the valves and the mass flow rate has been considered assumed. This approach can be considered suitable and even approximately lineal unless the valve is close to its maximum opening (see [26], [27]).

First the real system is analyzed at different operating points considering that the superheat at the evaporator outlet is fixed to $5 \mathrm{~K}$ by EV-2. At each point the intermediate pressure is modified, i.e. the aperture of the EVs, choosing the maximum COP as the best performance regardless the discharge pressure. Table 10 shows an example for (R290 ; 68/-8; Disp.Ratio=0.5407 ; UA=1), the displacement ratio corresponds to the optimum value for $\mathrm{R} 22$ and $-8 / 65$, but it has been taken the same for all operating points and refrigerants, the UA has been taken big enough to reach the highest COP in all cases. One should notice that for a different displacement ratio and UA the fitting curves might change, so they must be recalculated. It can be seen how the maximum COP is found when $\mathrm{DT}_{\mathrm{b}}$ and $\mathrm{DT}_{\mathrm{d}}$ tend to its minimum, as it was expected from the previous results. Furthermore it also coincides with the maximum subcooling at the economizer outlet.

The resulting mass flow ratio $\left(\mathrm{m}_{\mathrm{inj}} / \mathrm{m}_{\mathrm{ev}}\right)$ is plotted against the temperature gap between condenser and evaporator. Figure 8 shows this results for the three refrigerants included in this study. All of them have a linear tendency. Therefore the equation of the linear regression can be used to adjust 
the valves so as to work in the optimum conditions. The "valve equation" can be defined in terms of mass flow rate as:

$$
\frac{m_{i n j}}{m_{\text {main }}}=G \cdot\left(T_{C}-T_{E}\right)+o f f s e t
$$

were $G$ and offset are two constants depending on the refrigerant and the components of the system, $\mathrm{T}_{\mathrm{C}}$ is the condensing temperature, $\mathrm{T}_{\mathrm{E}}$ is the evaporating temperature and $\frac{m_{i n j}}{\dot{m}_{\text {main }}}$ is the ratio between the injected mass flow rate and the mass flow rate through the evaporator.

Table 11 shows the parameters from the linear fitting. Refrigerants R22 and R290 has a similar slope and R407C differ slightly. Based on this, once a system is defined (compressor volumes and economizer supplied), is it possible to define the optimum control from the point of view of COP for the intermediate valve based on a linear relation for the condensing and evaporating temperature.

The proposed methodology is an alternative to other control strategies available on the market like controlling the intermediate superheat. This second strategy is very useful from the point of view of reducing the compressor discharge temperature in fact usually this kind of control usually imposes low intermediate superheats but it is not optimum from the point of view of system COP. Table 8 shows that small changes in the intermediate pressure cause significant changes in the intermediate superheat which can introduce some problems in order to have precise control.

Finally, it has been observe that for the studied refrigerants, there is parabolic relationship between mass flow rate and the difference between evaporation and condensing temperatures exists when the control is made over the injection superheat (results not shown), hence the valve can be programed to follow this equation when the discharge temperature is too high. 


\section{Conclusions.}

The present work has analysed the vapour injection cycle as an alternative to the one stage compression cycles. A criterion for optimizing the intermediate working conditions as a function of the characteristic temperature difference of the system $\left(D T_{b}, D T_{d}\right)$ has been supplied. This criterion has shown that the variable $\mathrm{DT}_{\mathrm{b}}$ is much more influent on the optimum of the system than $\mathrm{DT}_{\mathrm{d}}$. Theoretically, vapour injection cycles have proved potential for improvement in the efficiency with regard to the one stage cycle, both in terms of COP (from 15\% to 20\%) and capacity (from $30 \%$ to $35 \%)$ for the considered nominal conditions.

Vapour injection cycles working with flash tank or economizer have been compared attending to the advantages and disadvantages of each one:

- Flash tank systems allow working close to the optimum of the system, greater capacities and lower discharge temperatures.

- Flash tank systems have the disadvantage of having constrained intermediate conditions.

- Economizer systems allow reaching the theoretical optimum of the system and it is very versatile in regard to its intermediate working conditions.

- Economizer systems have the disadvantage of having higher discharge temperatures.

The refrigerants with lower discharge temperatures have more improvement potential from the point of view of COP than refrigerants with higher discharge temperatures. The influence of the UA value of the economizer has been also analysed, obtaining that the increase in the heat exchanger area allows obtaining COP closer to the flash tank system and also reduces the compressor displacement for the same heating capacity.

Regarding the analysis performed in real systems,--the influence of the compressor efficiencies on the system has been shown. It is not possible to reach the theoretical COP optimum point due to 
the increase in the discharge temperature. The influence of the optimum design on the seasonal COP has been evaluated showing that a bad design of the displacement ratio could due to a loss of SCOP up to $6 \%$. These systems compared with one stage systems have shown a very significant improvement of the SCOP (more than 30\%) for applications of high temperature.

Finally, the control of the system has been analysed. It has been found that the optimum COP is obtained when the system has a maximum subcooling at the inlet of EV- 2 valve. A linear correlation for the ratio between $\left(\mathrm{m}_{\mathrm{inj}} / \mathrm{m}_{\mathrm{ev}}\right)$ as a function of the evaporating and condensing temperatures has been found. Taking into account that the mass flow rate through a valve can be related to the opening of the valve, this correlation allows the regulation of the injection expansion valve in order to obtain an optimum $\mathbf{C}_{\mathbf{o}}$. The advantages and disadvantages of this strategy compared to the control of the intermediate superheat have been defined.

Based on all this work, criteria for the sizing and control two stage systems have been established in order to define the optimum intermediate working conditions according to a given target: system reliability, performance and the like.

\section{Acknowledgements}

This work has been partially supported by the Spanish Ministerio de Economia y Competitividad through the project rsf. DPI 2011-26771-C02-01. The authors are grateful for the given support.

\section{References}

[1] Plan de ahorro y eficiencia energética 2011-2020. IDAE.

[2] http://ec.europa.eu/energy/index en.htm.

[3] Bertsch SS, Groll EA. 2008 Two-stage air-source heat pump for residential heating and cooling applications in northern U.S. climates. International Journal of Refrigeration. 31, 1282-1292. 
[4] Umezu, K. Suma, S. 1984. Heat pump room air conditioner using variable capacity compressor. ASHRAE Transactions. 90 335-349.

[5] Winady, EL, Lebrun, J., 2002. Scroll compressor using gas and liquid injection: experimental analysis and modeling. International Journal of Refrigeration 25, 1143-1156.

[6] Rasi, A., 1955. La pression intermédiare la plus correcte pour les cycles frigorifiques $a^{`}$ deux phases. IX International Congress of Refrigeration Paris 1, 3032-3039.

[7] Czaplinski, S., 1959. Uber den optimalen Zwischendruck bei Ka“"Iteprozessen. Allgemeine Wa"rmetechnik 91, 3-6.

[8] Baumann, K., Blass, E., 1961. Beitrag zur Ermittlung des Optimalen Mitteldruckes bei zweistufigen Kaltdampf Verdichter-Kaltemaschinen. Kaltetechnik 13, 210-216.

[9] Threlkeld, J.L., 1966. Thermal Environmental Engineering. Prentice-Hall, NJ.

[10]Arora, C.P., Dhar, P.L., 1971. Optimization of multistage refrigerant compressors. In: Proceedings of 13th International Congress of Refrigeration, vol. 2. IIR, Paris, pp. 693-700.

[11]De Lepeleire, G., 1973. Une nouvelle fac,on d'appreciation et de selection des compresseurs frigorifiques bietages. In: XIII International Congress of Refrigeration Washington, pp. 39-48.

[12]Gosney, W.B., 1982. Principles of Refrigeration. Cambridge University Press, Cambridge, UK.

[13]Domanski, P.A., 1995. Theoretical evaluation of the vapor compression cycle with a liquidline/suction-line heatexchanger, economizer, and ejector. NIST Interagency Report 5606. National Institute of Standards and Technology,Gaithersburg, MD.

[14]Zubair, S.M., Yaqub, M., Khan, S.H., 1996. Second-law-based thermodynamic analysis of twostage and mechanical subcooling refrigeration cycles. International Journal of Refrigeration 19 (8), 506-516.

[15]Vaisman, IB 2000. Economizer cycle in air conditioning systems with rotary vane compressors. In: Proc. of the 8th International Refrigeration Conference, West Lafayette, IN,USA, pp. 513-52 
[16]Ma, G. Chai, Q., 2004. Characteristics of an improved heat-pump cycle for cold regions. Applied Energy 77, 235-247.

[17]Ma, G. Chai, Q., Jiang, Y., 2003. Experimental investigation of airsource heat pump for cold regions. International Journal of Refrigeration 26, 12-18.

[18]Siddharth, J., Gauray, J., Clark, B., 2004. Vapor injection in scroll compressors. In: Proc. of International Compressor Engineering Conference, West Lafayette, IN, USA.

[19]Lifson, A. 2005. Novel vapor injection method for scroll compressors. In: Proc. of Int. Conference on Compressors and Their Systems, London, UK, pp. 381-390.

[20]Wang, B., 2005. Study on the scroll compressor with refrigerant injection and its application. Ph.D. dissertation, Department of Civil Engineering, Tsinghua University, Beijing, China.

[21]Wang, B., Li, X., Shi, W., Yan, Q., 2006. Effects of refrigerant injection on the scroll compressor. In: Proc. of International Compressor Engineering Conference, West Lafayette, IN, USA, C091.

[22]Wang, B., Li, X., Shi, W., Yan, Q., 2007a. Design of experimental bench and internal pressure measurement of scroll compressor with refrigerant injection. International Journal of Refrigeration 30, 179-186.

[23]Wang, X, Hwang, Y., Radermacher, R., 2008. Performance investigation of refrigerant vaporinjection technique for residential heat pump systems. In: Proc. of International Refrigeration and Air Conditioning Conference, West Lafayette, IN, USA, R2119.

[24]Sieres, J., Martínez-Suárez, J.A., Varas, F., Martínez, A.M., 2011. A simple method for calculating the maximum heat transfer rate of a counterflow heat exchanger. In: The $23^{\text {rd }}$ IIR Ibternational Congress of Refrigeration, Prague, Czech Republic.

[25]En 14825: Air conditioners, liquid chilling packages and heat pumps, with electrically compressors, for space heating and cooling testing and rating at part load conditions and calculation of seasonal performance. 
[26]C. Park, H. Cho, Y. Lee, Y. Kim. 2007. Mass flow characteristics and empirical modeling of R22 and R410A flowing through electronic expansion valves. International Journal of Refrigeration. $30,1401-1407$

[27]Wenhua Li. 2013. Simplified modeling analysis of mass flow characteristics in electronic expansion valve. Applied Thermal Engineering. 53, 8-12 


\section{List of Figures}

Figure 1. Vapour injection with economizer (left) and vapour injection with flash tank (right).

Figure 2. COP as a function of the limit temperature difference given in the equations (2) and (3).

With $D T_{b}=T_{\text {div }}-T_{\text {sec }}$ and $D T_{d}=T_{\text {main }}-T_{\text {bint }}$ at the working condition of (-8/65). a) Refrigerant $\left.R 290 . b\right)$ Refrigerant R22

Figure 3. COP versus displacement ratio. Ideal system with $\mathrm{DT}_{\mathrm{b}}=0$ and $\mathrm{DT} \mathrm{T}_{\mathrm{d}}=0$ at the working condition of $(-8 / 65)$ for R290

Figure 4. Economizer from a vapour injection cycle.

Figure 5. COP dependency on intermediate superheat for an injection system with economizer for an UA value of $700 \mathrm{~W} / \mathrm{K}$ at the working condition of $(-8 / 65)$ for R290.

Figure 6. Seasonal performance in active mode as a function of displacement ratio. Working conditions from [25], for R290, UA $=1$ and $\mathrm{sh}_{\text {int }}=5 \mathrm{~K}$

Figure 7. COP dependence on subcooling and displacement ratio. Ideal system with $\mathrm{DT}_{\mathrm{b}}=0$ and $D T_{d}=0$ at the working condition of $(-8 / 65)$ for $R 290$.

Figure 8. Ratio between injected mass flow rate and mass flow rate through the evaporator as a function of the temperature gap between condenser and evaporator. R290, UA=1 and displacement ratio $=0.5407$ 

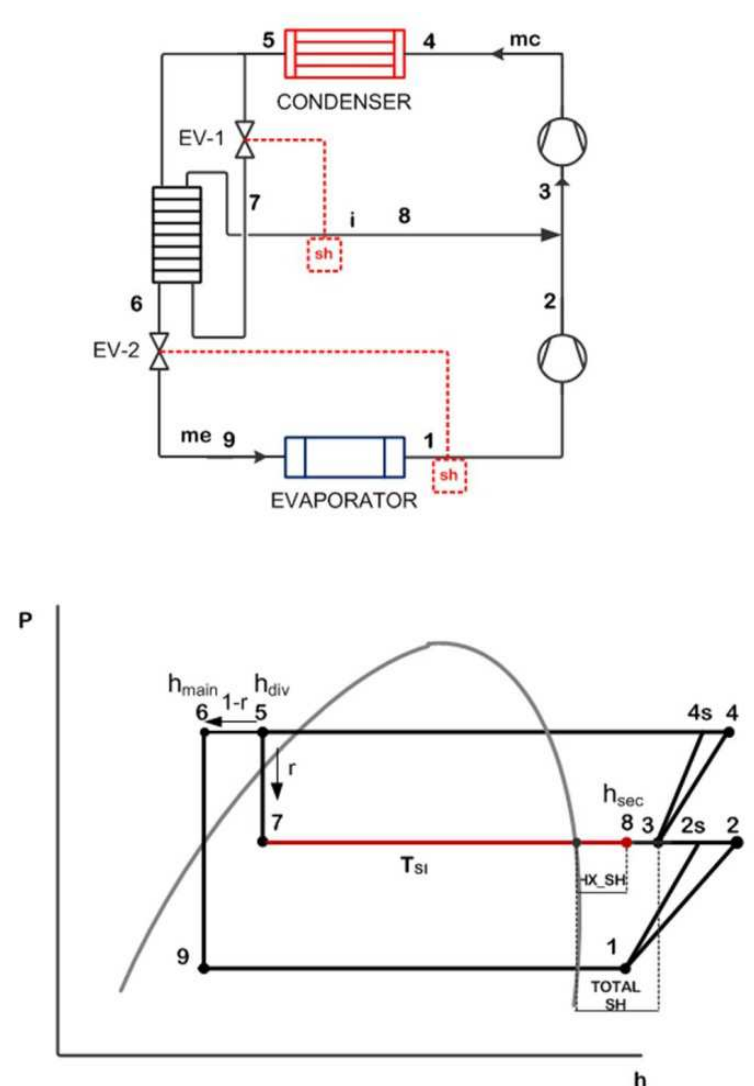
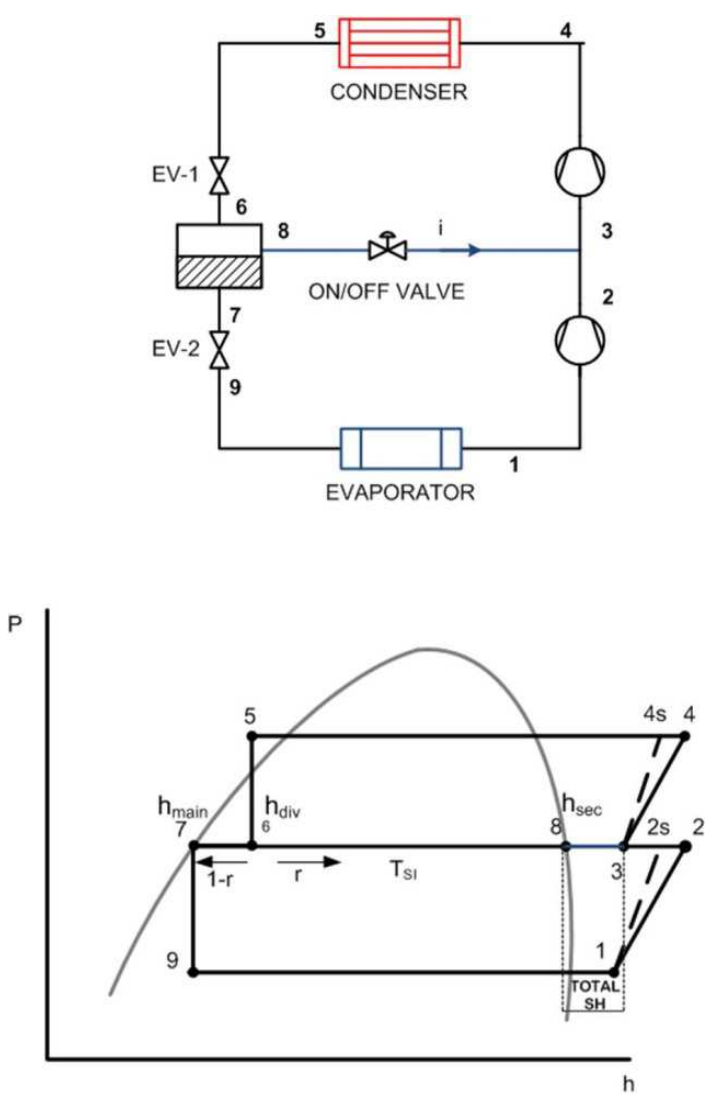

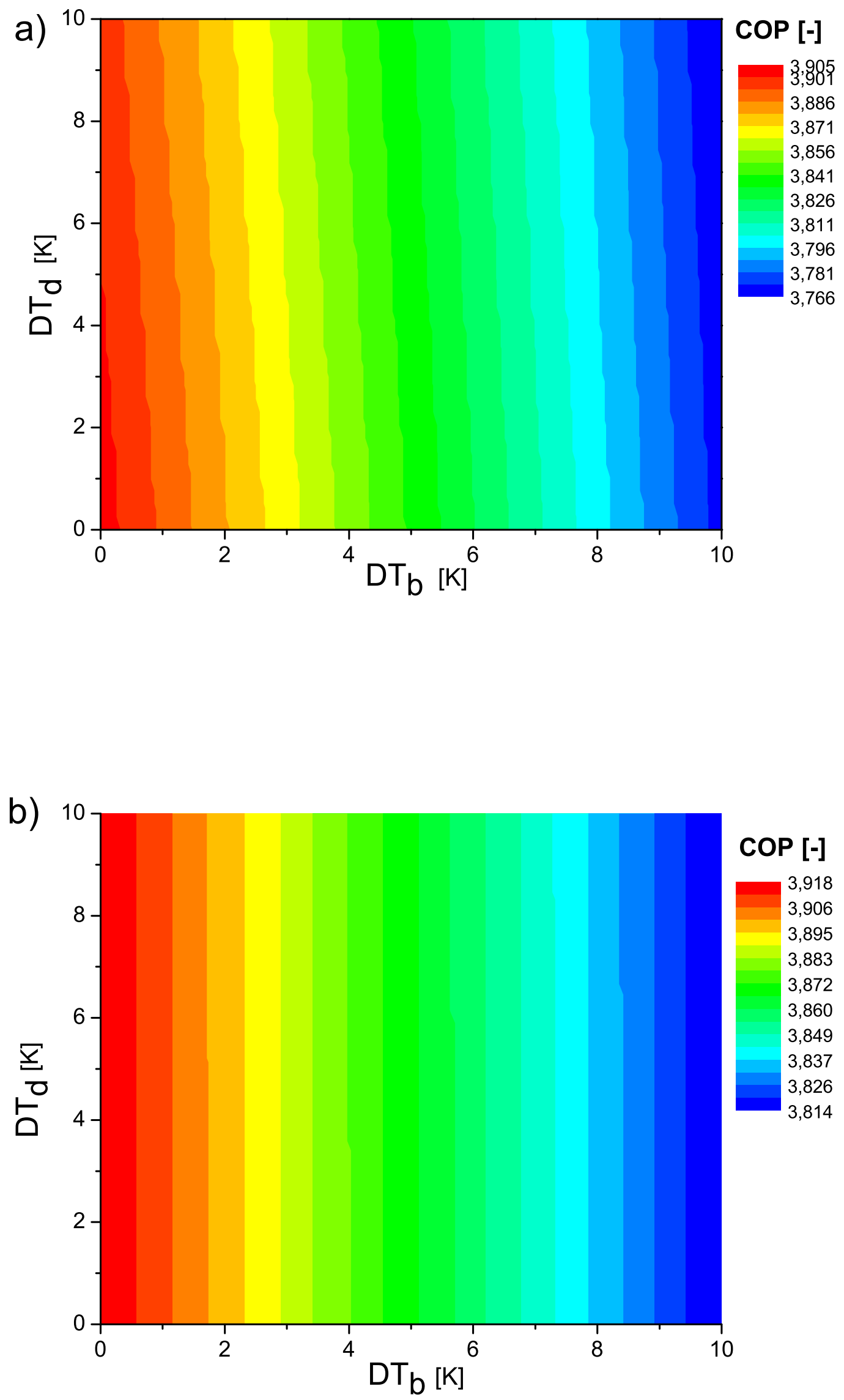


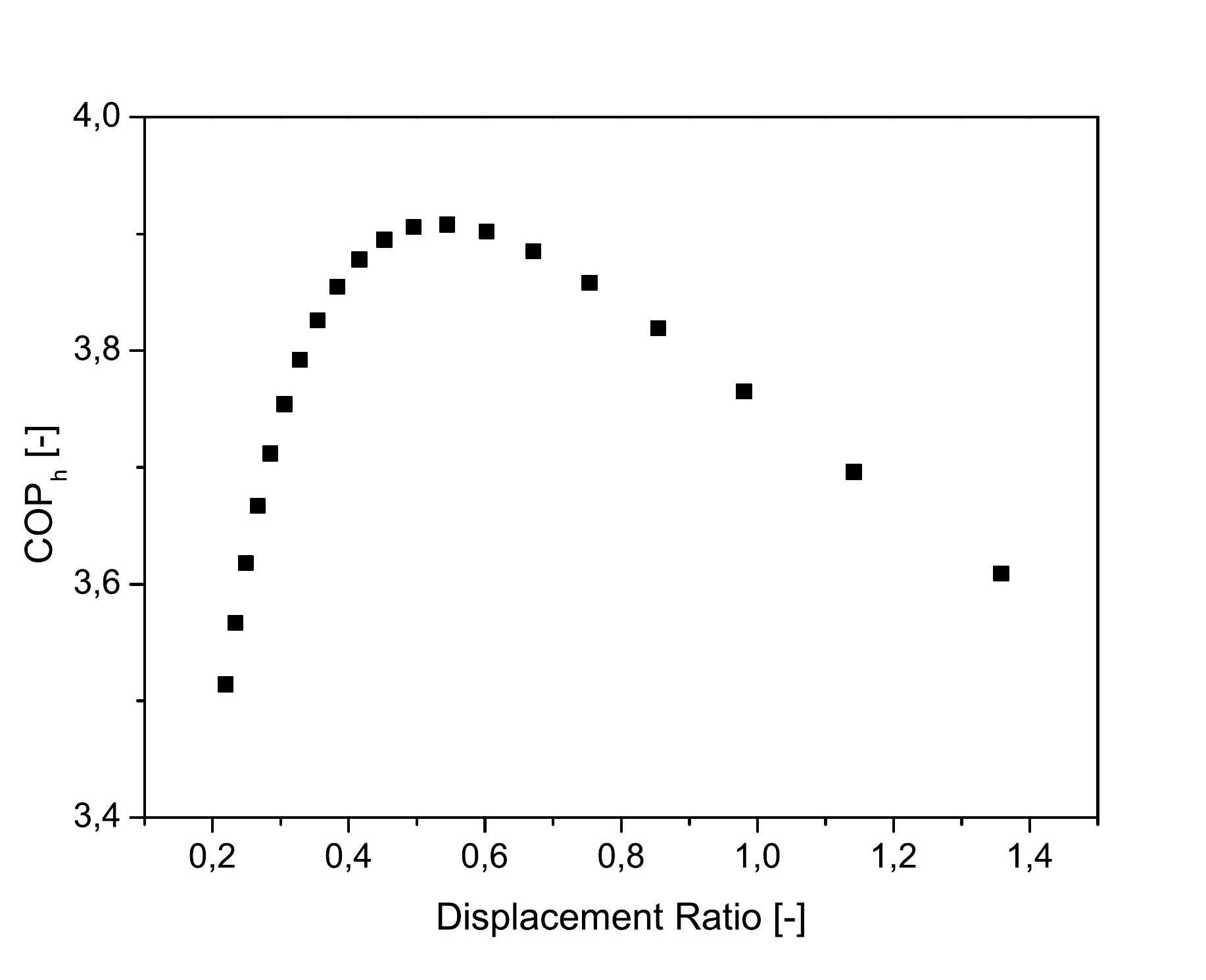

Figure

Figure

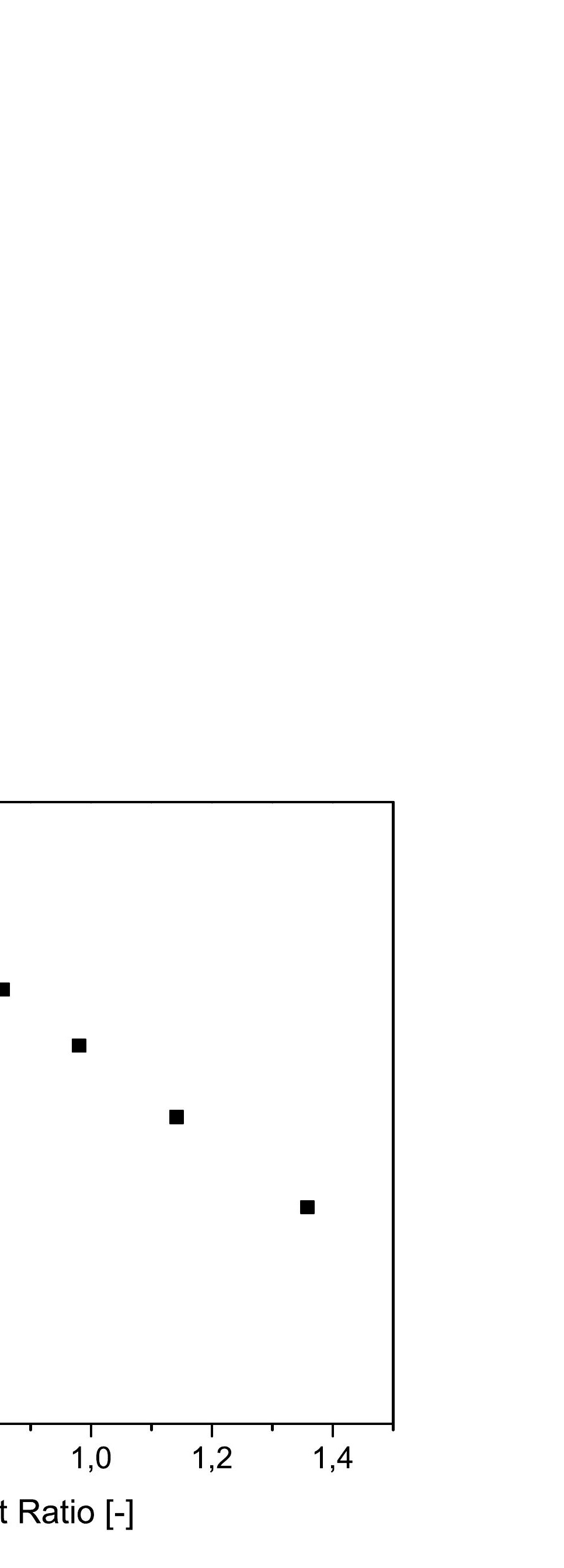





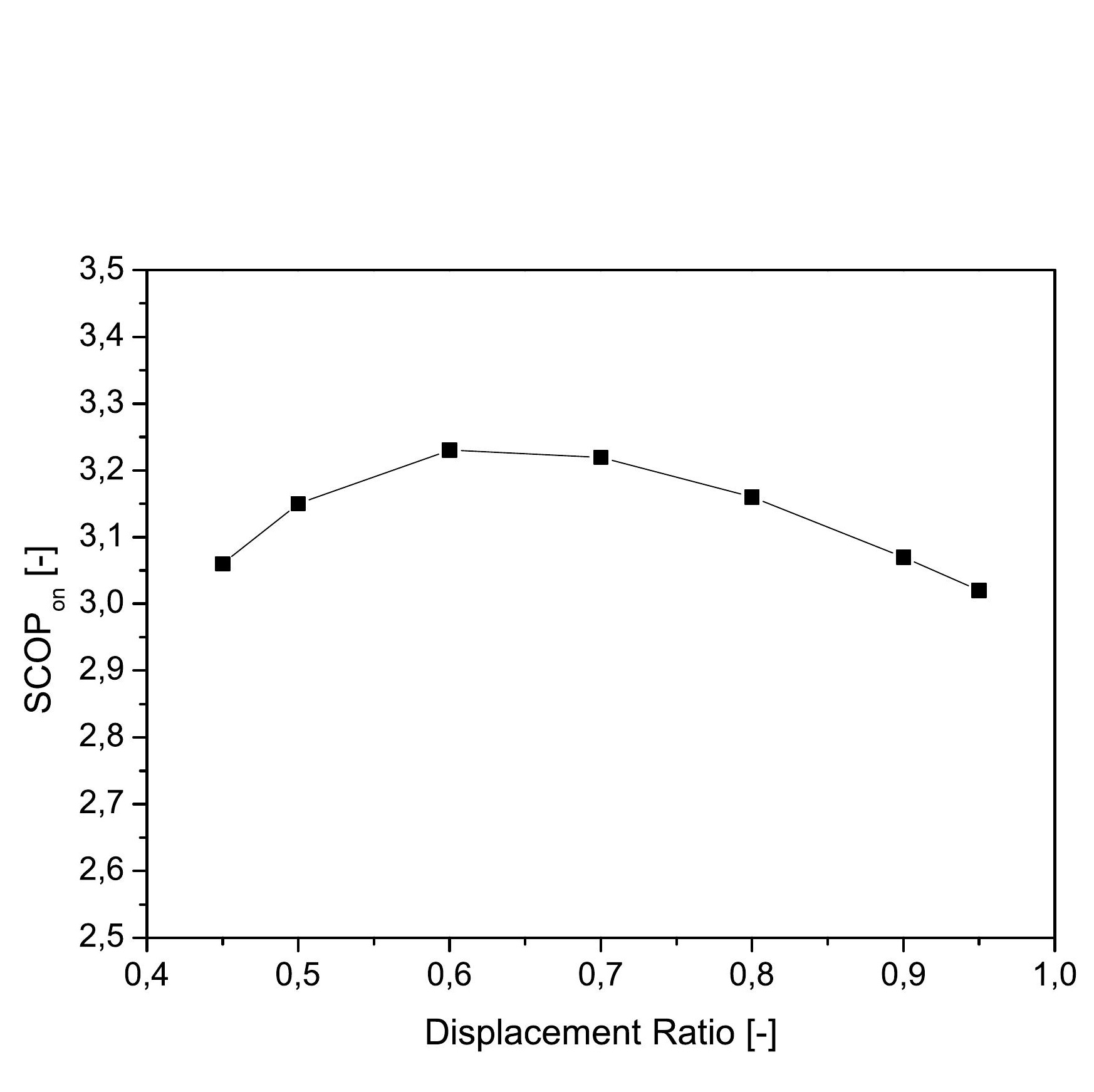

Figure

Figure

Fin

(1)

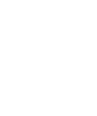




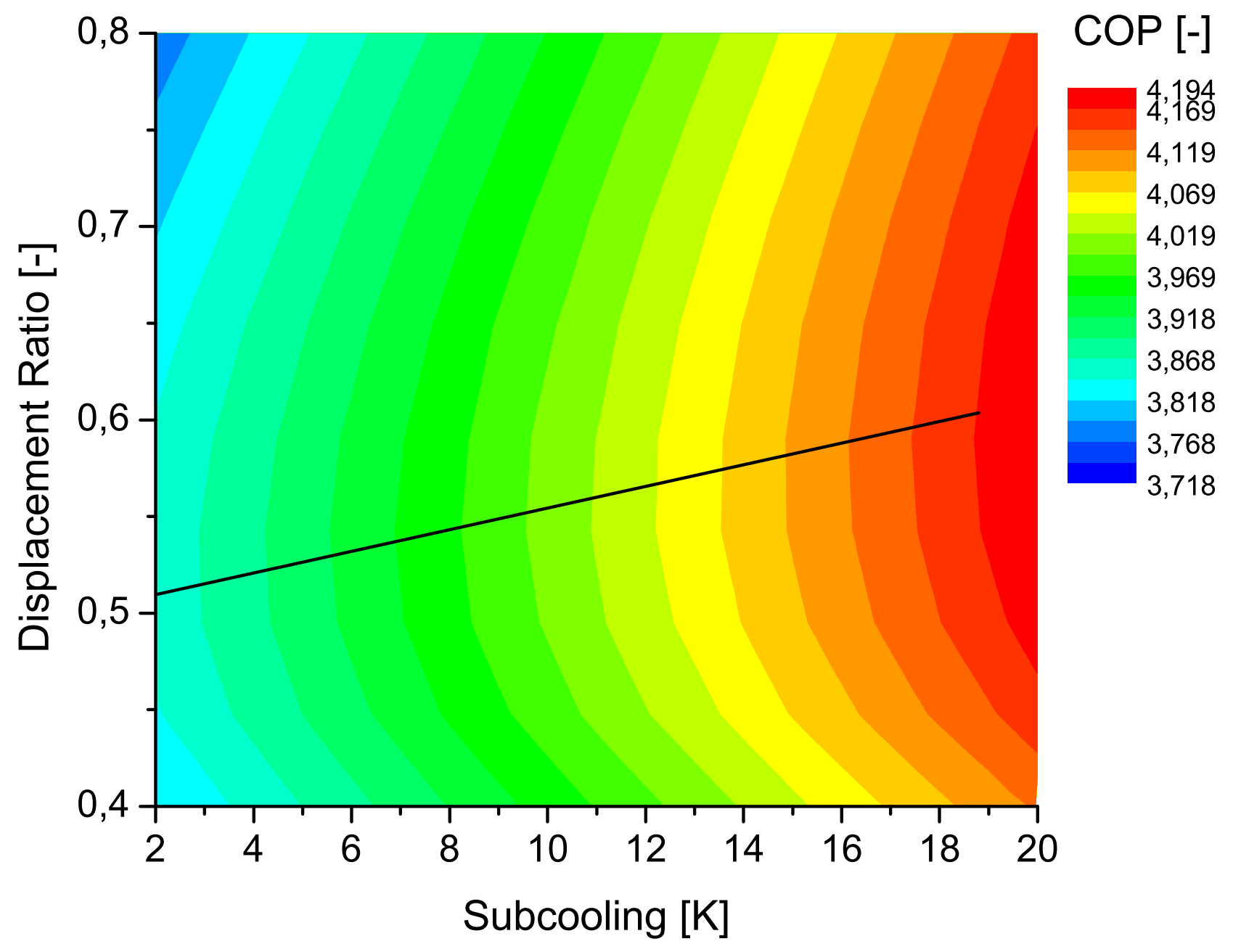




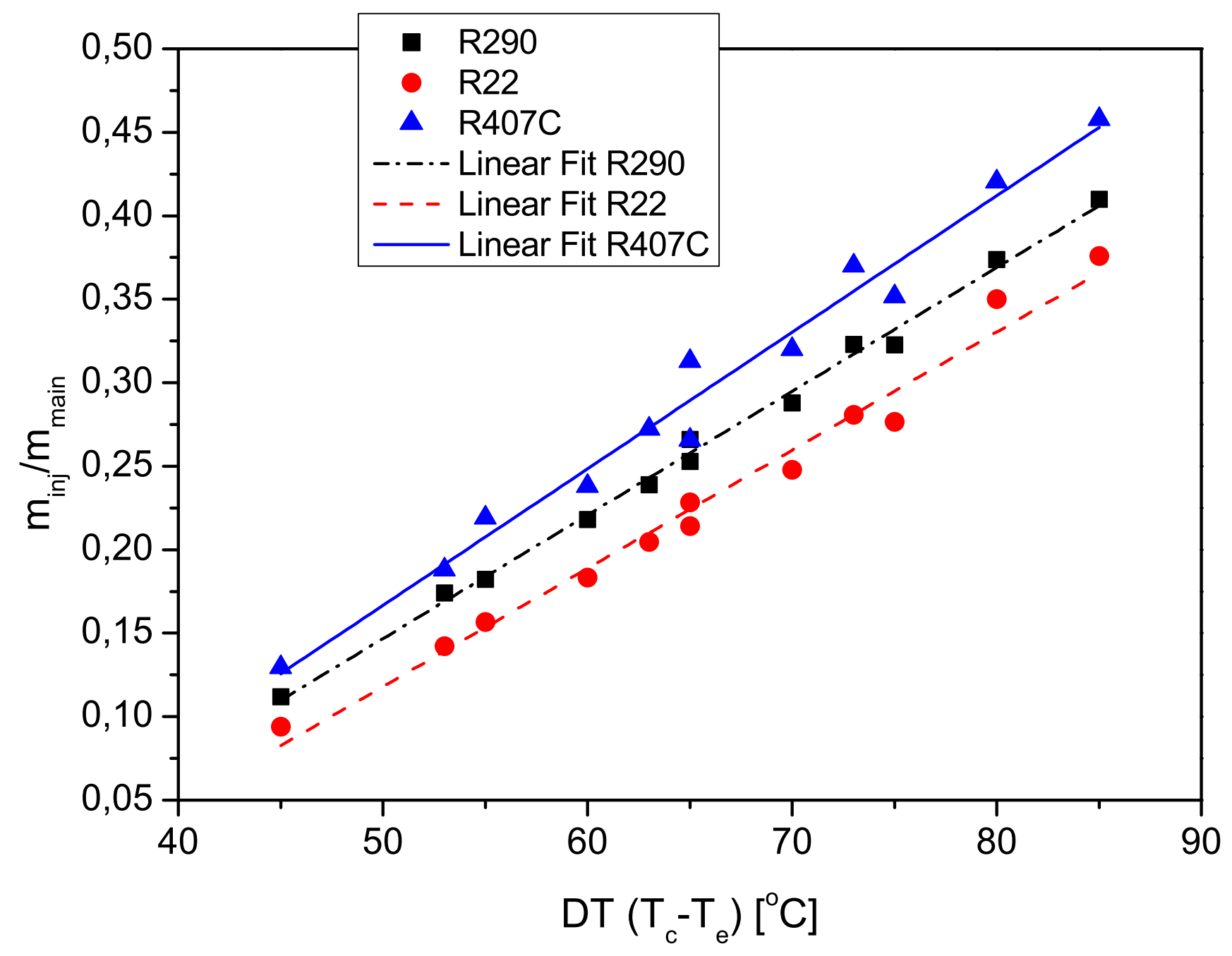




\begin{tabular}{|c|c|c|c|}
\hline Cycle & Relative efficiency (\%) & Relative capacity (\%) & Discharge temperature \\
\hline One stage & 100 & 100 & Very high \\
\hline $\begin{array}{c}\text { Two stage with } \\
\text { intermediate cooling }\end{array}$ & 130 & 140 & Low \\
\hline Two stage with injection & 130 & 150 & Low \\
\hline Cascade cycle & 130 & 140 & High \\
\hline Injection & 100 & 115 & Moderate \\
\hline Oil cooling & 100 & 100 & 120 \\
\hline Mechanical subcooling & 110 & & Very high \\
\hline
\end{tabular}

Table 1. Refrigeration cycles that are used for working under high compression ratio. 
Table

\begin{tabular}{|l|c|c|c|c|c|c|}
\hline & A & b & C & D & A & B \\
\hline Parameters & 1.41 & 0.21 & 0.52 & 0.30 & -0.025 & 1.02 \\
\hline
\end{tabular}

Table 2. Parameters of efficiency curves. 


\begin{tabular}{|c|c|c|c|c|c|c|c|c|c|c|}
\hline Ref & $\mathbf{X}_{\text {inj }}$ & $\mathbf{s h}_{\text {int }}$ & $\mathbf{P}_{\text {int }}$ & $\mathbf{T}_{\text {disch }}$ & $\mathbf{C}_{\mathbf{o}}$ & $\mathbf{C O P}_{\mathrm{h}}$ & $\mathbf{Q}_{\mathbf{h}}$ & $\begin{array}{c}\text { Disp. } \\
\text { ratio }\end{array}$ & $\mathbf{D Q}_{\mathrm{h}}$ & DCOP \\
\hline & {$[-]$} & {$[\mathrm{K}]$} & {$[\mathrm{kPa}]$} & {$\left[{ }^{\circ} \mathrm{C}\right]$} & {$[-]$} & {$[-]$} & {$[\mathrm{kW}]$} & {$[-]$} & $\%$ & $\%$ \\
\hline R407C & 0.2596 & 18.98 & 1105 & 94.45 & 1.122 & 3.748 & 16.97 & 0.46 & 35.3 & 17.6 \\
\hline R22 & 0.2114 & 24.65 & 1121 & 103.4 & 1.106 & 3.924 & 18.41 & 0.4901 & 28.4 & 13.2 \\
\hline R290 & 0.2458 & 15.25 & 994.2 & 81.97 & 1.07 & 3.908 & 16.19 & 0.5333 & 32 & 18 \\
\hline
\end{tabular}

Table 3. Injection cycle working in optimum intermediate conditions for the working point $(-8 / 65)$ 


\begin{tabular}{|c|c|c|c|c|c|c|c|c|c|c|c|c|}
\hline Ref & $\mathbf{X}_{\text {inj }}$ & $\mathbf{s h}_{\text {int }}$ & $\mathbf{P}_{\text {int }}$ & $\mathbf{T}_{\text {disch }}$ & $\mathbf{C}_{\mathrm{o}}$ & $\mathbf{C O P}_{\mathrm{h}}$ & $\mathbf{Q}_{\mathrm{h}}$ & $\begin{array}{c}\text { Disp. } \\
\text { ratio }\end{array}$ & $\mathbf{D Q}_{\mathrm{h}}$ & $\mathbf{D C O P}$ & $\mathbf{D T}_{\mathrm{b}}$ & $\mathbf{D T}_{\mathrm{d}}$ \\
\hline & {$[-]$} & {$[\mathrm{K}]$} & {$[\mathrm{kPa}]$} & {$\left[{ }^{\circ} \mathrm{C}\right]$} & {$[-]$} & {$[-]$} & {$[\mathrm{kW}]$} & {$[-]$} & $\%$ & $\%$ & {$[\mathrm{~K}]$} & {$[\mathrm{K}]$} \\
\hline $\mathrm{R} 407 \mathrm{C}$ & 0.2901 & 11.37 & 1134 & 87.19 & 1.151 & 3.741 & 16.84 & 0.4496 & 35.1 & 17.4 & 0 & 27.13 \\
\hline $\mathrm{R} 22$ & 0.2406 & 16.91 & 1105 & 96.04 & 1.09 & 3.913 & 18.37 & 0.4961 & 28.2 & 12.8 & 0 & 32.88 \\
\hline R290 & 0.2844 & 6.795 & 1037 & 74.46 & 1.116 & 3.888 & 15.98 & 0.5132 & 31.1 & 17.4 & 0 & 31.59 \\
\hline
\end{tabular}

Table 4. Vapour injection cycle with flash tank optimized for working at (-8/65) 


\begin{tabular}{|c|c|c|c|c|c|c|c|c|c|c|c|c|}
\hline Ref & $\mathbf{X}_{\text {inj }}$ & $\mathbf{s h}_{\text {int }}$ & $\mathbf{P}_{\text {int }}$ & $\mathbf{T}_{\text {disch }}$ & $\mathbf{C}_{\mathrm{o}}$ & $\mathbf{C O P}_{\mathrm{h}}$ & $\mathbf{Q}_{\mathrm{h}}$ & $\begin{array}{c}\text { Disp. } \\
\text { ratio }\end{array}$ & $\mathbf{D Q}_{\mathrm{h}}$ & $\mathbf{D C O P}$ & $\mathbf{D T}_{\mathrm{b}}$ & $\mathbf{D T}_{\mathrm{d}}$ \\
\hline & {$[-]$} & {$[\mathrm{K}]$} & {$[\mathrm{kPa}]$} & {$\left[{ }^{\circ} \mathrm{C}\right]$} & {$[-]$} & {$[-]$} & {$[\mathrm{kW}]$} & {$[-]$} & $\%$ & $\%$ & {$[\mathrm{~K}]$} & {$[\mathrm{K}]$} \\
\hline $\mathrm{R} 407 \mathrm{C}$ & 0.2637 & 12.53 & 1040 & 89 & 1.056 & 3.655 & 16.44 & 0.476 & 33.2 & 14.7 & 5 & 25.19 \\
\hline $\mathrm{R} 22$ & 0.2254 & 17.73 & 1047 & 97.66 & 1.033 & 3.868 & 18.17 & 0.5155 & 27.4 & 11.6 & 5 & 29.88 \\
\hline R290 & 0.2646 & 8.168 & 967.9 & 75.83 & 1.041 & 3.821 & 15.74 & 0.5401 & 30 & 15.4 & 5 & 29.37 \\
\hline
\end{tabular}

Table 5. Vapour injection cycle with economizer optimized for working at $(-8 / 65)$ 


\begin{tabular}{|c|c|c|c|c|c|c|}
\hline UA & $\mathbf{C O P}_{h}$ & $\mathbf{C}_{0}$ & $\mathbf{T}_{\text {disch }}$ & $\mathbf{Q}_{\mathrm{h}}$ & $\mathbf{D T}_{\mathrm{b}}$ & $\mathbf{D T}_{\mathrm{d}}$ \\
\hline$[\mathrm{W} / \mathrm{K}]$ & {$[-]$} & {$[-]$} & {$\left[{ }^{\circ} \mathrm{C}\right]$} & {$[\mathrm{kW}]$} & {$[\mathrm{K}]$} & {$[\mathrm{K}]$} \\
\hline Flash Tank & 3.888 & 1.116 & 74.46 & 15.97 & 0 & 31.59 \\
\hline 0,4 & 3,865 & 1,106 & 74,48 & 15,83 & 1,632 & 31,97 \\
\hline 0,5 & 3,877 & 1,111 & 74,47 & 15,91 & 0,7569 & 31,75 \\
\hline 0,6 & 3,883 & 1,114 & 74,46 & 15,94 & 0,3519 & 31,65 \\
\hline 0,7 & 3,886 & 1,115 & 74,46 & 15,96 & 0,1639 & 31,6 \\
\hline
\end{tabular}

Table 6. COP dependence on heat exchanger size and comparison with the flash tank system at working conditions of $(-8 / 65)$ with $\mathrm{R} 290$. 


\begin{tabular}{|c|c|c|c|c|}
\hline $\begin{array}{c}\text { Contour } \\
\text { Condition }\end{array}$ & Ref & C $[-]$ & Disp. Ratio [-] & $T_{\text {disch }}{ }^{\circ} \mathrm{C}$ ) \\
\hline \multirow{4}{*}{$-8 / 65$} & R407C & 1.031 & 0.5116 & 107.5 \\
\cline { 2 - 5 } & R22 & 1.028 & 0.5407 & 116.6 \\
\cline { 2 - 5 } & R290 & 1.035 & 0.5599 & 86.12 \\
\cline { 2 - 5 } $0 / 65$ & R407C & 1.019 & 0.5556 & 99.08 \\
\cline { 2 - 5 } & R22 & 1.015 & 0.5859 & 106.3 \\
\hline \multirow{3}{*}{$-20 / 65$} & R290 & 1.013 & 0.6089 & 81.7 \\
\cline { 2 - 5 } & R407C & 1.052 & 0.4485 & 127.2 \\
\cline { 2 - 5 } & R22 & 1.044 & 0.4795 & 139.7 \\
\hline
\end{tabular}

Table 7. Optimum design conditions for the three ambient conditions. Economizer cycle with an intermediate superheat of $5 \mathrm{~K}$. 


\begin{tabular}{|c|c|c|c|c|c|}
\hline $\begin{array}{l}\text { Contour } \\
\text { Condition }\end{array}$ & Ref & $\begin{array}{c}\mathrm{COP}_{\mathrm{h}} \text { (optimum } \\
\text { displacement } \\
\text { ratio) }\end{array}$ & $\begin{array}{l}\text { COP }_{h} \text { (design } \\
\text { displacement } \\
\text { ratio) }\end{array}$ & DCOP (\%) & $\mathrm{C}_{0}[-]$ \\
\hline \multirow{3}{*}{$-8 / 65$} & R407C & 2.822 & 2.822 & 0 & 1.031 \\
\hline & R22 & 3.053 & 3.053 & 0 & 1.028 \\
\hline & R290 & 3.092 & 3.092 & 0 & 1.035 \\
\hline \multirow{3}{*}{$0 / 65$} & R407C & 3.309 & 3.319 & 0.302 & 1.085 \\
\hline & R22 & 3.58 & 3.593 & 0.363 & 1.084 \\
\hline & R290 & 3.613 & 3.625 & 0.332 & 1.075 \\
\hline \multirow{3}{*}{$-20 / 65$} & R407C & 2.226 & 2.243 & 0.764 & 0.9463 \\
\hline & R22 & 2.411 & 2.428 & 0.705 & 0.9399 \\
\hline & R290 & 2.467 & 2.479 & 0.486 & 0.9698 \\
\hline
\end{tabular}

Table 8. COP degradation when the system works out of the nominal conditions. Economizer cycle 


\begin{tabular}{|c|c|c|c|c|c|c|c|}
\hline Subcooling & COPh $_{h}$ & $T_{\text {disch }}$ & $\mathbf{C}_{0}$ & $\begin{array}{c}\text { Dis. } \\
\text { ratio }\end{array}$ & $\mathbf{Q}_{\mathrm{h}}$ & $\mathbf{X}_{\text {inj }}$ & $\begin{array}{c}\text { Power } \\
\text { consumption }\end{array}$ \\
\hline$[\mathrm{K}]$ & {$[-]$} & {$\left[{ }^{\circ} \mathrm{C}\right]$} & {$[-]$} & {$[-]$} & {$[\mathrm{kW}]$} & {$[-]$} & {$[\mathrm{kW}]$} \\
\hline 2 & 3.852 & 82.75 & 1.099 & 0.524 & 16.119 & 0.262 & 4.185 \\
\hline 4 & 3.890 & 82.22 & 1.079 & 0.530 & 16.171 & 0.251 & 4.157 \\
\hline 8 & 3.964 & 81.23 & 1.042 & 0.544 & 16.264 & 0.230 & 4.103 \\
\hline 12 & 4.039 & 80.34 & 1.008 & 0.558 & 16.348 & 0.209 & 4.048 \\
\hline 16 & 4.114 & 79.54 & 0.977 & 0.573 & 16.424 & 0.188 & 3.992 \\
\hline 20 & 4.190 & 78.84 & 0.947 & 0.590 & 16.493 & 0.167 & 3.937 \\
\hline 24 & 4.266 & 78.23 & 0.920 & 0.608 & 16.557 & 0.146 & 3.881 \\
\hline 28 & 4.343 & 77.72 & 0.894 & 0.627 & 16.615 & 0.125 & 3.826 \\
\hline 40 & 4.576 & 76.81 & 0.826 & 0.696 & 16.765 & 0.060 & 3,664 \\
\hline
\end{tabular}

Table 1. Variation of different system variables as a function of subcooling for R290 for the optimum condition 


\begin{tabular}{|c|c|c|c|c|c|c|c|c|c|c|}
\hline Co & COP $_{\mathbf{h}}$ & $\begin{array}{c}\text { Subccoling } \\
\text { Economizer }\end{array}$ & $\mathbf{s h}_{\text {int }}$ & $\mathbf{Q}_{\mathbf{h}}$ & $\mathbf{x}_{\text {inj }}$ & $\mathbf{T}_{\text {disch }}$ & $\mathbf{D T}_{\mathbf{b}}$ & $\mathbf{D T}_{\mathbf{d}}$ & $\mathbf{m}_{\text {inj }}$ & $\mathbf{m}_{\text {main }}$ \\
\hline$[-]$ & {$[-]$} & {$[\mathrm{K}]$} & {$[\mathrm{K}]$} & {$[\mathrm{kW}]$} & {$[-]$} & {$\left[{ }^{\circ} \mathrm{C}\right]$} & {$[\mathrm{K}]$} & {$[\mathrm{K}]$} & {$[\mathrm{kg} / \mathrm{s}]$} & {$[\mathrm{kg} / \mathrm{s}]$} \\
\hline 1,072 & 3,144 & 32,097 & 33,139 & 16,650 & 0,240 & 92,783 & 1,091 & 0,049 & 0,01190 & 0,03775 \\
\hline 1,074 & 3,148 & 32,374 & 33,062 & 16,681 & 0,241 & 92,788 & 0,737 & 0,049 & 0,01199 & 0,03774 \\
\hline 1,077 & 3,151 & 32,651 & 32,986 & 16,712 & 0,243 & 92,793 & 0,384 & 0,049 & 0,01209 & 0,03774 \\
\hline 1,079 & 3,155 & 32,928 & 32,909 & 16,742 & 0,244 & 92,797 & 0,030 & 0,049 & 0,01218 & 0,03773 \\
\hline 1,081 & 3,153 & 32,870 & 28,123 & 16,737 & 0,250 & 91,747 & 0,012 & 4,759 & 0,01256 & 0,03773 \\
\hline 1,083 & 3,150 & 32,794 & 23,318 & 16,730 & 0,256 & 90,645 & 0,012 & 9,488 & 0,01296 & 0,03772 \\
\hline 1,085 & 3,147 & 32,717 & 18,741 & 16,722 & 0,262 & 89,548 & 0,012 & 13,988 & 0,01337 & 0,03772 \\
\hline
\end{tabular}

Table 10. Real system working at different intermediate pressures (R290 ; -8/65 ; Disp. Ratio=0.5407 ; UA=1). 